\title{
STUDY ON AVOCADO OIL QUALITY, ITS CHARACTERISTICS AND COMPOSITION
}

\author{
K.H.G.D.S. Premasiri \\ Reg. No.: - 00/AS/102
}

The Thesis is submitted to the University of Sri Jayewardenepura as the partial fulfillment requirement for the award of the degree of

\section{Master of Science}

In

Food Science and Technology

\author{
Department of Food Science and Technology \\ Faculty of Graduate Studies \\ University of Sri Jayewardenepura \\ Gangodawila \\ Nugegoda
}

October 2008 
AFFECTIONATE DEDICATION TO

MY PARENTS AND TEACHERS 


\section{Declaration}

The work described in this thesis was carried out by me as the partial fulfillment requirement for the degree of Master of Science in Food Science \& Technology under the supervision of Professor A. Bamunuarachchi, Department of Food Science \& Technology, Faculty of Applied Sciences, University of Sri Jayeardenepura. No similar report has been submitted to any other university for another degree.

K.H.G.D.S. Premasiri

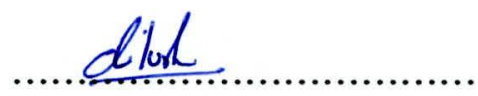

(GS/MSc/Food/2808/06)

Date:-..18.... 03.2009

I certified that the above statement made by the candidate is true and that the thesis is suitable for submission to the university for the purpose of evaluation.

Certified by,

Professor A. Bamunuarachchi,

Supervisor,

Department of Food Science \& Technology,

Faculty of Applied Sciences,

University of Sri Jayewardenepura,

Gangodawila,

Nugegoda

Sri Lanka.

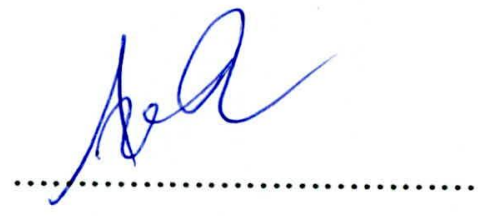

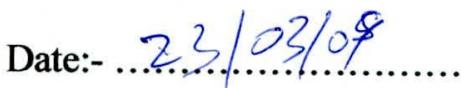




\begin{abstract}
Avocado is one of the most important crops grown in tropical and subtropical countries in the world and it is consumed mostly as a fresh fruit. Oil extracted from the fresh avocado pear has been a valuable product due its high stability. Avocado oil contains lots of nutritionally beneficial compounds. It has heart healthy monounsaturated fats, high level of pigments and vitamins ( $\alpha$ and $\beta$ carotene, vitamin $E$ ) which protect against heart diseases and cancers, minerals and valuable omega-3 fatty acids which help to lower blood cholesterol. Phytosterols and $\beta$-sterols inhibit intestinal cholesterol absorption in the human. Lutein is a natural antioxidant that may help to maintain eye health as we get older.
\end{abstract}

In this study, the oil content of different avocado varieties at different maturity stages was determined and the chemical and fatty acid composition of the extracted oil too was analyzed. The varieties selected for the experiment were Booth 7, Choquote, Fuerte, Purple Hybrid, Reed, Simmonds, Tower II, and Waldin. The physical characteristics of each variety were observed and measured. The oil extracted from these varieties by soxhlet extraction method was analyzed for chemical characteristics and the fatty acid composition by gas chromatography. The proximate analysis of the residue remaining after the oil extraction was also carried out.

Fruit shape, size, colour, and skin were found to the most prominent physical characteristics useful in identifying the avocado varieties. According to the results, the oil content of the avocado fruit of each variety increases with its maturity level. The rates of increasing oil content decreases as the fruits become mature.

The highest oil contents were found in Fuerte, Tower II and Reed varieties, hybrids of Mexican and Gautemalan cultivars. Booth 7 variety a hybrid of Gautemalan x West Indian cultivars had medium oil content. All low oil content varieties belong to West Indian Cultivar. Avocado oil has a similar composition to edible oils when compared with the chemical composition of other edible oils and it is similar to olive oil in many respects.

The study showed that avocado oil is composed of Palmitic Acid (C16:0), Palmitoleic Acid (C16:1), Stearic Acid (C:18:0), Oleic Acid (C18:1), Linoleic Acid (C18:2), and Linolenic Acid (C 18:3). Fuerte variety has the higher percentage of unsaturated fatty acid that is $\mathbf{7 7 . 2} \%$. Tower II variety has $66.9 \%$ and Waldin variety has $66.7 \%$. The Oleic Acid is the most abundant unsaturated fatty acid in all three varieties i.e Fuerte $-56.14 \%$, Tower II $-39.02 \%$ and Waldin $-40.10 \%$. 


\section{ACKNOWLEDGEMENT}

I wish to express my foremost appreciation to my supervisor Professor A. Bamunuarachchi, Department of Food Science \& Technology, Faculty of Applied Science, University of Sri Jayeardenepura for his invaluable guidance and kind corporation rendered to me to complete the project successfully.

I extend my sincere gratitude to Dr. S. Sarananda, Head, Food Research Unit, Department of Agriculture, Gannoruwa and Professor H.M.D. Heenkenda, RSO, Agriculture Farm, Department of Agriculture, Gannoruwa for the kind assistance given to me for obtaining avocado samples as required for the research.

I also extend my thanks to the staff members of the Department of Food Science \& Technology, Faculty of Applied Sciences, University of Jayewardenepura, for the valuable support given to me.

My special thanks to the laboratory staff of Adamjee Lukmanjee and Sons Limited and SGS Lanka Pvt. Limited for their kind assistance given to me. 


\section{LIST OF FIGURES}

Figure 2.1 Centers of Origin for the Ecological Races of Avocado 3

$\begin{array}{lll}\text { Figure 2.2 Reproductive Structures of Avocado } & 7\end{array}$

$\begin{array}{lll}\text { Figure } 2.3 \text { The Avocado Fruit } & 8\end{array}$

Figure 2.4 Fuerte Variety - Fruit 9

$\begin{array}{lll}\text { Figure 2.5 Reed Varieties - Fruit } & 10\end{array}$

$\begin{array}{lll}\text { Figure 2.6 Booth } 7 \text { Variety - Fruit } & 11\end{array}$

Figure 2.7 Pollock Variety - Fruit 12

$\begin{array}{lll}\text { Figure } 2.8 \text { Waldin Variety - Fruit } & 12\end{array}$

$\begin{array}{lll}\text { Figure 2.9 Tower II Variety - Fruit } & 13\end{array}$

$\begin{array}{lll}\text { Figure 2.10 Simmonds Variety - Fruit } & 14\end{array}$

$\begin{array}{lll}\text { Figure 2.11 Purple Hybrid Variety - Fruit } & 14\end{array}$

Figure 2.12 Respiratory Rate and Ethylene Production At $20^{\circ} \mathrm{C}$ in Fuerte Avocados Following Harvest (o-o $\mathrm{CO}_{2}$, o-o Ethylene) 16

Figure 4.1 Change in Moisture and Oil Content with Maturity of Fuerte Variety 49

Figure 4.2 Change in Moisture and Oil Content with Maturity of Reed Variety 50

Figure 4.3 Change in Moisture and Oil Content with Maturity of Tower II Variety 51

Figure 4.4 Change in Moisture and Oil Content with Maturity of Waldin Variety 52

Figure 4.5 Change in Moisture and Oil Content with Maturity of Simmonds Variety 53

Figure 4.6 Change in Moisture and Oil Content with Maturity of Purple Hybrid Variety 54

Figure 4.7 Change in Moisture and Oil Content with Maturity of Booth 7 Variety 55

Figure 4.8 Change in Moisture and Oil Content with Maturity of Choquette Variety 56

Figure 4.9 Moisture Content of Matured Avocado Fruits of Different Varieties 57

Figure 4.10 Oil Content of Matured Avocado Fruits of Different Varieties 58

Figure 4.11 Avocado Oil Samples $\quad 59$

Figure 4.12 Average Oil Yield - 100 of Matured Avocado Fruits of Different $\begin{array}{ll}\text { Varieties } & 60\end{array}$

Figure 4.13 Fatty Acid Composition of Avocado Oil - Fuerte Variety 64

Figure 4.14 Fatty Acid Composition of Avocado Oil - Tower II Variety 65

Figure 4.15 Fatty Acid Composition of Avocado Oil - Waldin Variety 66

Figure 4.15 Fatty Acid Composition of Avocado Oil 67 


\section{LIST OF TABLES}

Table 2.1 Major Countries Producing Avocado 4

Table 2.2 Avocado Production Targets for Year $2006 \& 2008$ in Sri Lanka 5

Table 2.3 Average Nutrition Composition (on a Fresh-Weight Basis) of Avocado Fruit

Table 2.4 Principal Fatty Acids 21

Table 2.5 Fatty Acid Composition of Different Edible Oils 22

Table 2.6 Chemical Composition of Different Edible Oils 23

Table 2.7 Fatty Acid Composition of Avocado Oil 24

Table 2.8 Chemical Composition of Avocado Oil 25

Table 4.1 Physical Characteristics of Selected Avocado Varieties 45

Table 4.2 Seed : Pulp Ratio and Fruit Size of Different Avocado Varieties 46

Table 4.3 Change in Moisture and Oil Content with Maturity of Fuerte Variety 49

Table 4.4 Change in Moisture and Oil Content with Maturity of Reed Variety 50

Table 4.5 Change in Moisture and Oil Content with Maturity of Tower II Variety 51

Table 4.6 Change in Moisture and Oil Content with Maturity of Waldin Variety 52

Table 4.7 Change in Moisture and Oil Content with Maturity of Simmonds Variety 53

Table 4.8 Change in Moisture and Oil Content with Maturity of Purple Hybrid Variety 54

Table 4.9 Change in Moisture and Oil Content with Maturity of Booth 7 Variety 55

Table 4.10 Change in Moisture and Oil Content with Maturity of Choquette Variety 56

Table 4.11 Physical Properties of Avacado Oil of Different Varieties 59

Table 4.12 Average Oil Content of Matured Avocado Fruit $\quad 60$

Table 4.13 Specific Gravity of Avocado Oil of Different Varieties 61

Table 4.14 Acid Value of Avocado Oil of Different Varieties 61

Table 4.15 Iodine Value of Avocado Oil of Different Varieties 62

Table 4.16 Saponification Value of Avocado Oil of Different Varieties 62

Table 4.17 Unsaponified Matter of Avocado Oil of Different Varieties 63

Table 4.18 Protein Content of Avocado Residue of Different Varieties $\quad 68$

Table 4.19 Fiber Content of Avocado Residue of Different Varieties 68

Table 4.20 Total Ash Content of Avocado Residue of Different Varieties 69

Table 4.21 Oil Content of Avocado Residue of Different Varieties 69

Table 4.22 Moisture Content of Avocado Residue of Different Varieties $\quad 69$ 


\section{ABBREVIATIONS}

GC - Gas Chromatography

e.g. - Example

i.e. - That is

Sp.Gr. - Specific Gravity

$\mathrm{NaOH}$ - Sodium Hydroxide

$\mathrm{HCl}$ - Hydrochloric Acid

$\mathrm{KOH}$ - Potassium Hydroxide

$\mathrm{BF}_{3}-$ Boron Trifloride

$\mathrm{NaCl}$ - Sodium Chloride

$\mathrm{Na}_{2} \mathrm{SO}_{4}$ - Sodium Sulfate

$\mathrm{H}_{2} \mathrm{SO}_{4}$ - Sulfuric Acid

ppm - parts per million 


\section{TABLE OF CONTENTS}

Abstract

page

Acknowledgement

i

List of Figures

ii

List of Tables

iii

Abbreviations

iv

$\mathrm{V}$

\section{Chapter 1- Introduction}

1.1 Introduction

1.2 Overall Objectives 2

1.3 Specific Objectives 2

\section{Chapter 2 - Literature survey}

2.1 Introduction to Avocado 3

2.1.1 Origin and Distribution 3

2.1.2 Avocado PRoduction 4

2.1.3 Taxonomy and Classification 5

2.2 Botany 7

2.3 Avocado Varieties $\quad 8$

$\begin{array}{ll}2.4 \text { Propagation } & 15\end{array}$

2.5 Fruit Development $\quad 15$

2.6 Fruit Ripening $\quad 15$

$\begin{array}{ll}2.7 \text { Harvesting } & 16\end{array}$

$\begin{array}{ll}2.8 \text { Diseases and Pests } & 17\end{array}$

2.9 Environmental Conditions Required for Avocado Cultivation 17

2.10 Nutrition Composition of Avocado $\quad 18$

2.11 Avocado Oil $\quad 20$

2.11.1 The Basic Chemistry of Fats and Oils 20

2.11.2 Composition of Common Edible Oils $\quad 21$

2.11.3 Composition of Avocado Oil 24

2.11.4 Extraction of Avocado Oil 25

2.11.5 Uses of Avocado Oil 26

2.12 Fat and Oil Processing $\quad 28$ 


\section{Chapter 3 - Methodology}

$\begin{array}{lr}3.1 \text { Sample Collection } & 29\end{array}$

3.1.1 Location $\quad 29$

3.1.2 Selected Varieties $\quad 29$

$\begin{array}{ll}\text { 3.1.3 Fruit Collection } & 29\end{array}$

3.2 Fruit Assessment 30

$\begin{array}{ll}\text { 3.2.1 Physical Characteristics } & 30\end{array}$

3.2.2 Quantitative Determination of Moisture Content (Dry Matter) of

Avocado Fruits 30

3.2.3 Quantitative Determination of Lipid / Oil Content of Avocado Fruits 31

3.3 Chemical Analysis of Avocado Oil 32

3.3.1 Specific Gravity $\quad 32$

3.3.2 Acid Value $\quad 33$

3.3.3 Iodine Value $\quad 34$

3.3.4 Saponification Value $\quad 35$

3.3.5 Unsaponified Matter 36

3.3.6 Fatty Acid Composition $\quad 37$

3.3.6.1 Conversion of Triglycerides to Fatty Acid Methyl Ester (FAME) 38

3.3.6.2 Gas Chromatography Analysis $\quad 38$

3.4 Proximate Analysis of Avocado Residue Remains after Oil Extraction 39

3.4.1 Determination of Protein 39

3.4.2 Determination of Fiber 41

3.4.3 Determination of Total Ash 42

3.4.4 Determination of Oil Content 43

$\begin{array}{ll}\text { 3.4.5 Determination of Moisture } & 43\end{array}$

\section{Chapter 4 - Results and Discussion}

4.1 Fruit Assessment

44

4.1.1 Physical Characteristics 44

4.1.2 Quantitative Determination of Moisture Content and Lipid / Oil

Content of Avocado Fruits $\quad 48$

4.2 Chemical Analysis o Avocado Oil $\quad 61$

$\begin{array}{ll}\text { 4.2.1 Specific Gravity of Oils } & 61\end{array}$

$\begin{array}{ll}4.2 .2 \text { Acid Value } & 61\end{array}$ 
4.2.3 Iodine Value $\quad 62$

$\begin{array}{ll}\text { 4.2.4 Saponification Value (Sap Value) } & 62\end{array}$

$\begin{array}{ll}\text { 4.2.5 Unsaponified Matter } & 63\end{array}$

4.2.6 Fatty Acid Analysis $\quad 63$

4.3 Proximate Analysis of Avocado Residue Remains after Oil Extraction 68

4.3.1 Determination of Protein $\quad 68$

$\begin{array}{ll}\text { 4.3.2 Determination of Fiber } & 68\end{array}$

$\begin{array}{ll}\text { 4.3.3 Determination of Total Ash } & 69\end{array}$

$\begin{array}{ll}\text { 4.3.4 Determination of Oil Content } & 69\end{array}$

$\begin{array}{ll}\text { 4.3.5 Determination of Moisture } & 69\end{array}$

$\begin{array}{ll}\text { Chapter 5 - Conclusion } & 71\end{array}$

$\begin{array}{ll}\text { Chapter 6 - Recommendations } & 72\end{array}$

$\begin{array}{ll}\text { References } & 73\end{array}$

$\begin{array}{ll}\text { Appendix } & 75\end{array}$ 


\section{CHAPTER 1 \\ INTRODUCTION}

\subsection{Introduction}

Avocado (Persea Americana) is an edible fruit, belongs to the Family Lauraceae. It is native to the tropical and subtropical regions of North and South America and has been spread to all tropical countries in the world (Condit, 1915). Avocado tree is an evergreen tree that attains heights of $20 \mathrm{~m}$ and has many branches.

The fruit of avocado is referred to as a berry, consisting of a single carpel and a single seed (Salunkhe et al, 1991). The fruit may be round, pear shaped, or oblong, and the skin of the fruit may vary in texture and color. The skin of the fruit may be pliable to woody, smooth to rough, and green-yellow, reddish-purple, purple, or black in color. The flesh of the fruit is greenish yellow to bright yellow when ripe and buttery in consistency, but inferior varieties may be fibrous. The avocado fruit has one large seed which makes up to $10.0 \%-25.0 \%$ of the fruit weight. Avocado fruits range from $150 \mathrm{~g}$ to more than $1.25 \mathrm{~kg}$ in weight.

The edible pulp of the avocado, which surrounds the seed, contains from $8.0 \%-30.0 \%$ of non-drying oil. Oil is separated by dehydrating the pulp, then pressing or extracting with solvents. It has been recognized that there is a close relationship between the oil content and the development of an avocado fruit. Basically, oil content increases as the fruit matures. It also depends on cultivar.

Oil is the most important component of avocado fruit as it is a significant proportion of the dry matter of the mesocarp $(60 \%-80 \%)$. It is responsible for the taste and mouth feel that govern consumer demand for avocados. The oil is mainly composed of oleic acid. The predominant use of the avocado oil to date is mostly because of the high stability of the oil and its vitamin $\mathrm{E}$ ( $\alpha$-tocopherol) content.

Avocado oil contains a variety of nutritionally beneficial compounds. It has the highest level of heart healthy monounsaturated fats, high level of pigments ( $\alpha$ and $\beta$ carotene) which protect against heart diseases and cancers, vitamins and minerals (especially vitamin E- a 
powerful antioxidant) and valuable omega-3 fatty acids which helps to lower blood cholesterol level.

Avocado oil is used as a food oil, as an ingredient in other dishes, as well as a cooking oil. It can be found frequently in cosmetics where it is valued for its regenerative and moisturizing properties. It also functions well as a carrier oil for other flavors. As a culinary oil, avocado oil compares well with olive oil. Avocado oil is one of the most valuable oils of the unsaturated fatty acids range.

Avocado oil is of high importance to the cosmetic industry. This is mostly due to the high stability of the oil and its vitamin E content. Vitamin A in avocado oil helps to prevent from dry skin and vitamin $\mathrm{E}$ and vitamin $\mathrm{D}$ are effective against skin wrinkling. Due to the abundance of unsaturated fatty acids and fibrous proteins in avocado oil, it acts as a natural skin moisturizer and makes the skin look soft and young. Avocado oil also has some sun screening properties.

Avocado is a fruit rich in other nutritional factors as well. Therefore the residue of the avocado pulp remaining after the oil extraction has a good nutritive value. Value addition to the residue will increase the demand for the by product.

\subsection{Overall Objective}

1. To determine the oil content of different avocado varieties and analysis of its fatty acid composition and nutritional composition.

\subsection{Specific Objectives}

1. To identify the suitable varieties and correct maturity level of the fruit which can be used to extract maximum oil yield.

2. To determine the characteristics of avocado oil.

3. To determine the fatty acid composition of the extracted oil.

4. To determine the nutritional composition of avocado residue and possible value addition. 


\section{CHAPTER 2}

\section{LITERATURE REVIEW}

\subsection{Introduction to Avocado}

Avocado is one of the important crops grown in tropical and subtropical countries in the world. It is consumed mostly as a fresh fruit and has good dietary value. It is a high fat fruit, which contains rare sugars of high carbon numbers and relatively rich in certain vitamins, minerals and nitrogenous substances. Due to its high oil and low sugar content it is recommended as a high energy food for diabetics. Avocado oil is in great demand for the preparation of cosmetics. In Western Europe imports of avocados has increased several fold in the last decades (Salunkhe et al, 1995).

\subsubsection{Origin and Distribution}

The avocado fruit was first described by Martin Fernandez de Encisco Sevilla Spain in 1591 (Human, 1987). It was originated in a broad geographical area stretching from the Eastern and Central highlands of Mexico through Guatemala to the Pacific coast of Central America (Whiley et al, 2002). From its native home it has spread to all tropical countries.

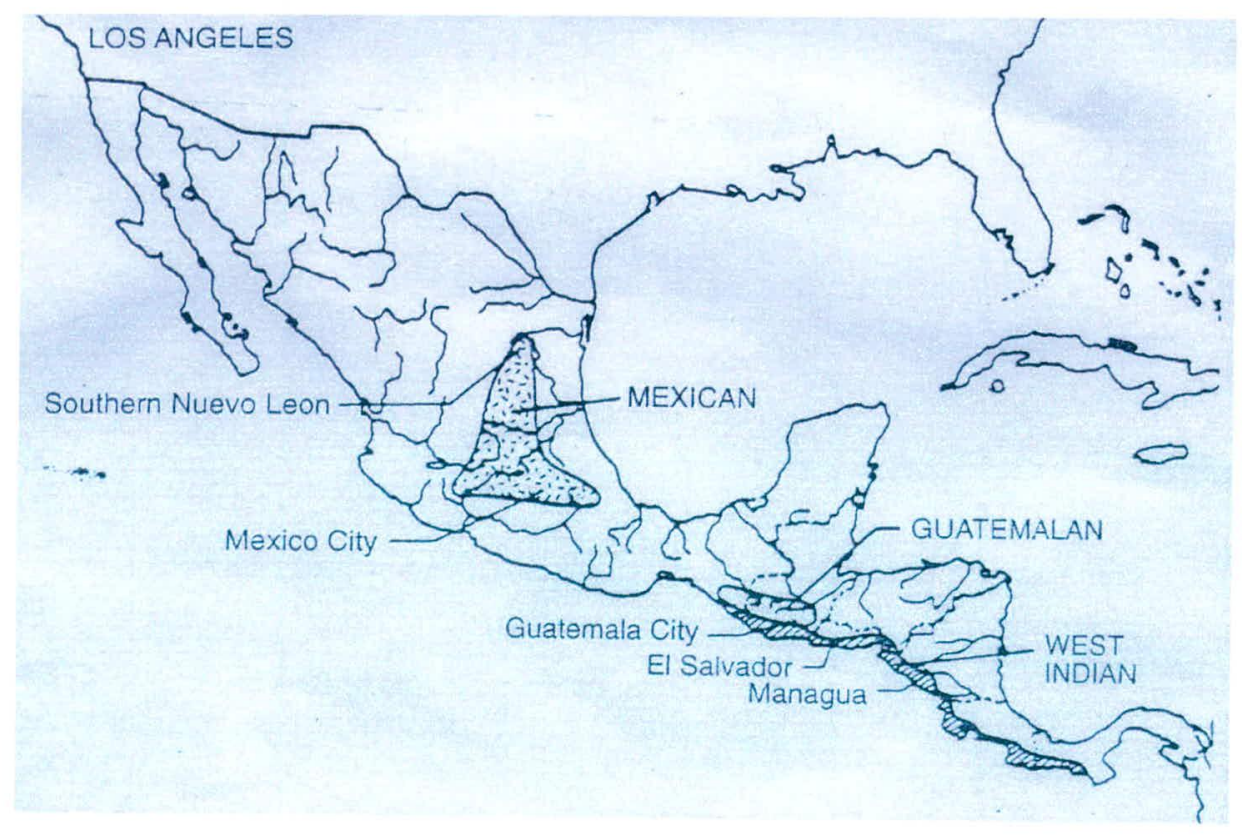

Figure 2.1 : Centers of Origin for the Ecological Races of Avocado

Source : Whiley et al, 2002 
In 1918 the British Imperial Institute in England drew attention to the possibility of using avocado oil as a source of oil being suitable for edible purposes. The first avocado oil was extracted commercially in 1958 at Polittsi, Nothern Transvaal (Human, 1987).

The date of introduction of avocado to Sri Lanka is not known. However records at Department of Agriculture indicate that bud grafts of some avocado varieties were established successfully in the Royal Botanical Garden, Peradeniya in May 1927 (Nethsinghe, 1993).

\subsubsection{Avocado Production}

Avocado is mainly grown in tropical and subtropical climates particularly in America and Asia. Mexico, the United States, the Dominican Republic, Brazil, Colombia and many other countries of South America, Central America, the Caribbean Islands and South Africa are the main avocado producing countries in the world (Salunkhe et al, 1995). The world avocado production is about 1, 463, 000 MT (Salunkhe et al, 1995) and Mexico and United States are the largest producers supplying over one third of the world's total production.

Table 2.1 : Major Countries Producing Avocado

\begin{tabular}{|l|c|}
\hline \multicolumn{1}{|c|}{ Country } & Production (1000 MT) \\
\hline Mexico & 320 \\
\hline United States & 160 \\
\hline Dominical Republic & 133 \\
\hline Brazil & 115 \\
\hline Colombia & 81 \\
\hline Indonesia & 72 \\
\hline Haiti & 58 \\
\hline Venezuela & 49 \\
\hline Zaire & 45 \\
\hline Chilie & 40 \\
\hline South Africa & 35 \\
\hline Spain & 35 \\
\hline Gautemala & 29 \\
\hline Peru & 25 \\
\hline Philippines & 22 \\
\hline
\end{tabular}

Source : Salunkhe et al, 1995 